\title{
Accuracy, inter-observer and intra-observer reliability in topography assessment of multifocal contact lens centration
}

Fabrizio Zeri ${ }^{1-3}$, Assunta Di Vizio ${ }^{4}$, Maurizio Guida ${ }^{4}$, Anastasia Rotondi ${ }^{4}$, Silvia Tavazzi ${ }^{1,2}$ Shehzad A. Naroo ${ }^{3}$

${ }^{1}$ University of Milano Bicocca, Department of Materials Science, via R. Cozzi 55, I-20125 Milan, Italy

${ }^{2}$ University of Milano Bicocca, COMiB Research Centre in Optics and Optometry, via R. Cozzi 55, I-20125 Milan, Italy

${ }^{3}$ School of Life and Health Sciences, Aston University, Birmingham, UK

${ }^{4}$ Degree Course in Optics and Optometry, Department of Sciences. Roma TRE University, Rome, Italy

Corresponding author:

Fabrizio Zeri

University of Milano Bicocca

Department of Materials Science

via R. Cozzi 55

I-20125 Milan, Italy

Phone: +390264485035

e-mail: fabrizio.zeri@unimib.it

Declaration of interest: none.

This research did not receive any specific grant from funding agencies in the public, commercial, or not-for-profit sectors. During the period of the research, Dr Fabrizio Zeri was funded with the support of the European Union under a Marie Curie Intra-European Fellowship for Career Development (FP7), Grant Agreement number 622786. 


\section{ABSTRACT}

Purpose

To evaluate the accuracy and reliability (inter and intra-observer) of a novel method to assess multifocal contact lenses (MCLs) centration using a corneal topography unit.

Method

Daily-disposable MCLs (Fusion 1 day Presbyo) were fitted on both eyes of the subjects. For each lens fit a slit lamp digital picture and videokeratograph image were taken in a rapid but randomised sequence. Photo-editing software was used to assess the position of the MCL centre with respect to pupil centre as taken from the slit lamp photograph. The position of the MCL centre was automatically detected as the point of maximum curvature from the videokeratography. Three further manual and qualitative procedures to detect MCL centre, comparing a template of CLs optic zones to the videokeratographic image were performed by 4 practitioners using 3 different algorithms to represent the topographic map. Each manual reading was repeated 3 times.

Results

Twenty-two subjects (11 males) aged 22.8 \pm 1.9 years (range 20.8-27.0 years) were recruited. The accuracy of the 4 topographic assessments in determining the centre coordinates of the MCL with respect to SL assessment was good: no differences were found in the left eyes and although in the right eyes a more temporal and superior position of MCLs was determined (paired t-test, $\mathrm{p}<0.05)$ the difference was clinically negligible $(0.16 \pm 0.36 \mathrm{~mm}$ horizontally, $0.23 \pm 0.48$ vertically). Amongst the 4 practitioners one-way Anova for repeated measures showed no differences for any of the 3 manual assessments. Intra-class correlation coefficient was calculated amongst the 3 readings for each manual procedure and was very good (between 0.75 and 0.98 ) in 3 practitioners and moderate (between 0.49 and 0.92 ) in the fourth. 


\section{Conclusions}

The assessment of MCL centration by performing corneal topography over the MCL is an accurate method. Furthermore, inter and intra-practitioner reliability showed by manual procedures appeared very good.

Key words: Presbyopia, multifocal contact lenses, topography. 


\section{Introduction}

Since the first soft bifocals contact lens (CL) were produced in 1977 (Lamb and Bowden, 2018) many designs of bifocal, multifocal, progressive, and diffractive soft CLs have been proposed and introduced to the market to correct presbyopia. In the latest Contact Lens and Solutions Summary (White, 2018) there have been 48 different brands of multifocal contact lenses (MCL) listed as available in US market.

All these different designs work on the simultaneous-imaging principle (Charman, 2014). In the vast majority of MCLs there is a rotationally symmetric change in the power from the optical centre to the edge of the optical zone. This can modify the spherical aberration of the ocular system either in a positive direction, in case of centre-distance design MCL, or in negative direction in case of centre-near design MCL (Plainis, 2013; Perez-Prados et al, 2017). The increase in spherical aberration enhances the depth of focus of the eye irrespectively of the sign of this change (Bakaraju et al, 2010 even though this depends on the interaction with the specific ocular spherical aberration in which the lens is fitted. On the other hand, this improvement causes a superimposition of multiple images, more or less blurred, on the retina that determines a contrast sensitivity reduction due to a drop in the modulation transfer function (MTF) (Bakaraju et al 2010; Nio et al 2002).

The patient satisfaction with the quality of vision provided by simultaneous-imaging CLs is quite different. This wide inter-individual variability can be due to optical, physiological, and psychophysical factors that are not simple to predict during the initial MCL fitting (Diec et al 2017; Zeri et al 2019).

More recently MCLs with higher positive power towards the edge of the optical zone of the lens, almost similar to a centre-distance design MCL for presbyopia, have been proposed to compensate for the peripheral hyperopic defocus which has been pointed as one possible factor inducing myopia progression (Sankaridurg et al 2011, Walline et al 2013; Sankaridurg \& Holden, 2014).

One important factor that can massively impact the effectiveness of the correction and the final visual outcomes with MCLs, either fitted for presbyopia correction or myopia control, is the centration of the lens (Woods et al 1993). Decentration of a MCL will cause unwanted aberrations, mainly represented by coma (Dave, 2015; Perez-Prados et al, 2017). However, a certain debate about the optimum reference axis (pupil axes, visual axes, line of sight) on which placing the optical centre of a MCLs or the centre of multifocal laser treatment or even 
for measuring the optical aberrations of the eye, is still ongoing (Applegate et al, 2000; Mosquera, 2015).

Many procedures to evaluate CLs centration have been proposed in literature mainly by the use of the slit lamp (e.g. Wolffsohn el al, 2009). However, these procedures do not allow fine measurement of the decentration of the lens with respect to an ocular landmark, such as the pupil cenret. A potentially finer procedure to assess the position of a MCL has been suggested (Lampa et al, 2012), where it proposes the use of a corneal topography performed both without and over the MCL which allows to detect the position of the centre inferred by the tangential power difference display map. This procedure could help in clinical setting in understanding the results of the fitting, minimizing follow-ups (Miller and Brujic, 2012). This procedure has been recently used to assess the centration of scleral lenses (Vincent \& Collins, 2019), directly by the use of a single topography measure (tangential power map) with the CL in place. However, no information is available about the accuracy and reliability of this method for assessing centration in case of MCLs. In order to address this lack of evidence, a study was performed to evaluate accuracy in MCL centration assessment with topography performed over the CL and to evaluate inter and intra-examiner reliability in assessing CL centration with the same technique.

\section{Method}

The study was carried out in different phases (Figure 1).
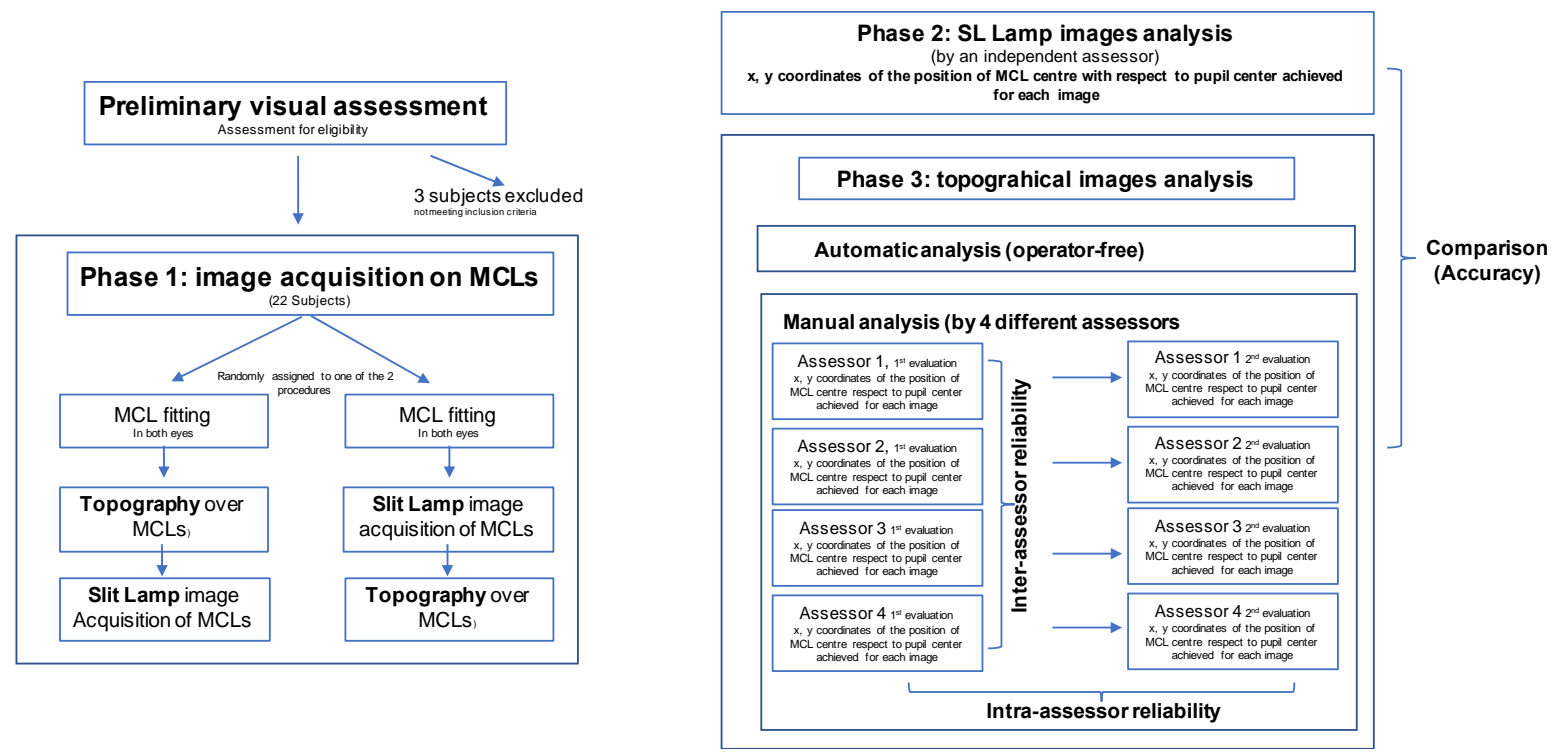

Figure 1. Flow diagram of the study design. 


\section{Phase 1:}

In this first clinical phase, images of MCLs fitted in volunteers were collected.

\section{Participants}

The study involved twenty-two volunteers (11 females), recruited from amongst the students of the Optics and Optometry Degree Course of Roma TRE University (Rome) with a mean age of $22.8 \pm 1.9$ years (range 20.8-27.0 years) (Table 1). No evidence or history of visual anomalies or ocular pathologies were specific selection criteria for the candidates. Subjects with corneal irregular astigmatism and/or corneal astigmatism over 3.00 DC were not considered. The study followed the tenets of the Declaration of Helsinki, the study followed the institutional ethical guidelines and all participants provided informed consent preceded by an explanation of the procedures of the study.

Table 1. Demographic and optometric information of participants.

\begin{tabular}{|c|c|}
\hline & Whole sample $(n=22)$ \\
\hline $\begin{array}{l}\text { Gender } \\
\text { Men } \\
\text { Women }\end{array}$ & $\begin{array}{l}11(50 \%) \\
11(50 \%)\end{array}$ \\
\hline $\begin{array}{l}\text { Age (years) } \\
\text { Mean } \pm \text { SD (min;max) }\end{array}$ & $22.8 \pm 1.9(20.8 ; 27.0)$ \\
\hline $\begin{array}{l}\text { MSE* (D) right eye } \\
\text { Mean } \pm \text { SD (min;max) }\end{array}$ & $-1.73 \pm 1.86(-6.63 ; 0.50)$ \\
\hline $\begin{array}{l}\text { MSE* (D) left eye } \\
\text { Mean } \pm \text { SD (min;max) }\end{array}$ & $-1.39 \pm 2.07(-6.63 ; 1.50)$ \\
\hline $\begin{array}{l}\text { Mean corneal astigmatism (D) right eye } \\
\text { Mean } \pm \mathrm{SD}(\min ; \max )\end{array}$ & $1.10 \pm 0.72(0.00 ; 2.90)$ \\
\hline $\begin{array}{l}\text { Mean corneal astigmatism (D) left eye } \\
\text { Mean } \pm \text { SD (min;max) }\end{array}$ & $0.96 \pm 0.64(0.00 ; 2.58)$ \\
\hline $\begin{array}{l}\text { Number of subjects for type of corneal } \\
\text { astigmatism (D) right eye }\end{array}$ & $\begin{array}{l}\text { - } 19 \text { with the rule astigmatism (steepest corneal } \\
\text { meridian } 90^{\circ} \pm 20^{\circ} \text { ); } \\
\text { - } 1 \text { against the rule astigmatism (steepest corneal } \\
\text { meridian } 180^{\circ} \pm 20^{\circ} \text { ); } \\
\text { - } 1 \text { oblique astigmatism (steepest meridian between } \\
21^{\circ} \text { and } 69^{\circ} \text { or } 111^{\circ} \text { and } 159^{\circ} \text { ) } \\
\text {. } 1 \text { spherical cornea. }\end{array}$ \\
\hline $\begin{array}{l}\text { Number of subjects for type of corneal } \\
\text { astigmatism (D) left eye }\end{array}$ & $\begin{array}{l}\text { - } 19 \text { with the rule astigmatism (steepest corneal } \\
\left.\text { meridian } 90^{\circ} \pm 20^{\circ}\right) \text {; } \\
\text {. } 2 \text { oblique astigmatism (steepest meridian between } \\
21^{\circ} \text { and } 69^{\circ} \text { or } 111^{\circ} \text { and } 159^{\circ} \text { ); } \\
\text {. } 1 \text { spherical cornea. }\end{array}$ \\
\hline
\end{tabular}

\footnotetext{
*mean spherical equivalent
} 


\section{Materials}

The CLs used were daily disposable MCL (Fusion 1 day Presbyo, Safilens, Staranzano, Italy) in Filcon IV with $60 \%$ of water content, with a back optic zone radius of $8.6 \mathrm{~mm}$, a total diameter of $14.5 \mathrm{~mm}$, a Dk/t $\left(\times 10^{-9}\right)$ of $29(\mathrm{~cm} / \mathrm{s})\left(\mathrm{mLO}_{2} / \mathrm{mL} \mathrm{mmHg}\right)$, and a central thickness of $0.07 \mathrm{~mm}(@-3.00 \mathrm{D})$. Multifocal CL had plano (0.00 D) labeled power for distance. The lens was characterised by a small central area of hyperprolature (i.e. according the manufacturer a hyper-refractive central area) with a diameter of the entire optic zone of $10 \mathrm{~mm}$. The manufacturer does not describe properly the lens as a MCL but instead as a lens with a patented afocal design. However, considering the presence of a hyper-refractive central area on the lens we decided to maintain the term MCL to describe the lens through the paper.

\section{Procedure}

Each volunteer underwent a preliminary examination to determine his/her eligibility for the study according the inclusion criteria. The same licensed clinician carried out all the assessment procedures. After having recorded the case history of each single participant the clinician performed a slit lamp assessment to investigate for any cornea disease, a videokeratography to assess for any corneal topographical anomaly and a refraction (see Table 1)

In a following session each enrolled participant was fitted with the MCL chosen for the experiment. All the MCLs were fitted by the same researcher (researcher A). After a 15-minute period of adaptation to MCLs, two procedures to acquire images of the MCL were performed in rapid (within approximately 2 minutes for all procedures) and randomised sequence, to both eyes by the same researcher (researcher B):

i) A digital picture taken with a slit lamp (FS-3, Nikon, Japan).

This image allowed an evaluation of (see phase 2) the "true" position of MCLs (gold standard) to determine the accuracy of the new method (topographical image, as discussed on point ii) studied in the experiment. The illuminating arm of slit lamp was placed 15 degrees on the left of biomicrosope axis that was always perpendicular to patient's cornea. The subject put his/her chin on the chinrest and, in order to allow a good alignment between the line of sight of the eye pictured in the photo with the optical axis of the instruments, the contralateral eye was covered with a movable occluder descending from the front rest and placed at $2 \mathrm{~cm}$ from the eye. Furthermore, the subject was asked to fix exactly in the centre of the objective lens of the slit lamp which was connected to the camera by a beam splitter. Pictures 
were shot $1 \mathrm{~s}$ after the blinking. Pictures out of focus, with unclear edges of the MCL, and with any artifacts (blinking, movements, etc.) were discharged and only one picture for each eye of each participant was selected.

ii) A topographical image acquired over the MCL by a videokeratography (Eye-Top, CSO, Italy).

The subject put his/her chin on the chinrest and in order to allow a good alignment between the line of sight of the eye with the optical axes of the instruments, the contralateral eye was covered with a movable occluder descending from the front rest and placed at $2 \mathrm{~cm}$ from the eye. Furthermore, the subject was asked to fix exactly in the centre of the fixation light of the topographer. Image was acquired one second after the blinking.

The operator checked immediately that the corneal sighting centre and the optical axes (Zeri, 2012) of the instrument were coincident, if this was not the case, the acquisition was repeated. Only one topographical image from each eye of each participant was selected.

\section{Phase 2:}

In this second phase, the 44 images (22 from right eyes and 22 from left eyes) of MCLs acquired in phase 1 from Slit Lamp were analysed. The images captured with the slit lamp (i) were analysed through a photo-editing procedure to assess the position of the MCL centre with respect to pupil centre in a Cartesian plane (Figure 2). Starting from the original digital picture, the edges of MCL was traced with an Image Editor Program (Microsoft Paint 2007). A circular digital template was aligned overlapping to the circumference of MCL. The same procedure, using an appropriate pupil template, was also performed to detect the pupil centre. Relative distance between two centres was estimated from digital line length joining them, converting pixel to $\mathrm{mm}$, according to a calibration worked out in a pre-experiment phase. The position of the MCL centre was determined with respect to the pupil centre in $x$ and $y$ coordinates. This represented the 'true' position of reference with which to compare the position of the MCL centre determined by the topographical procedure. 


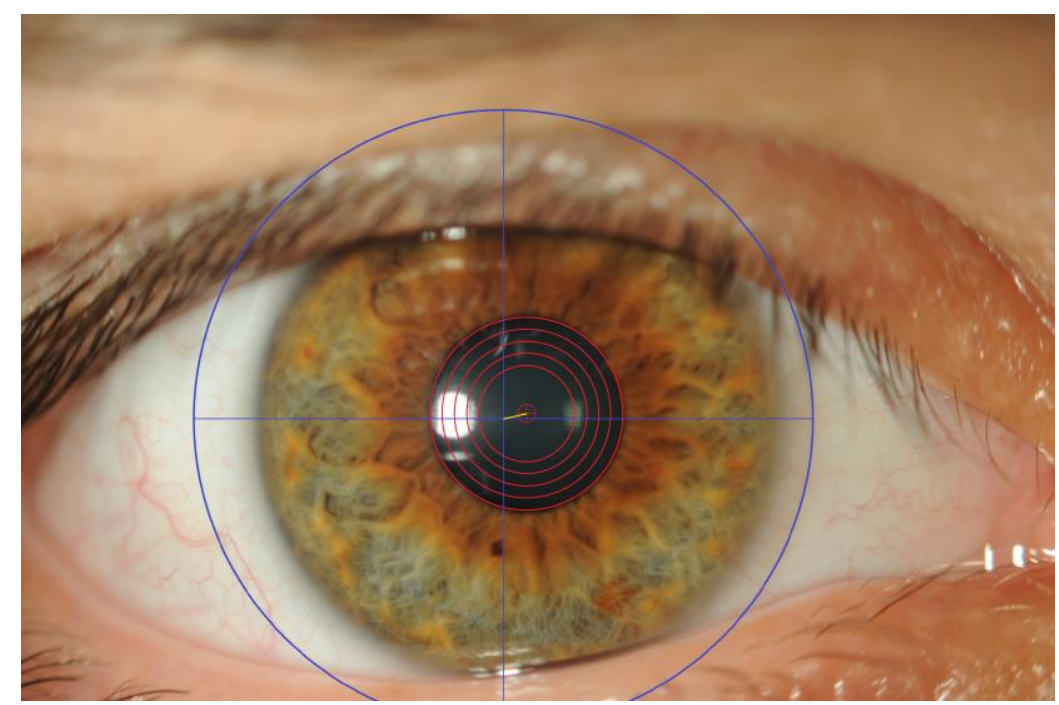

Figure 2. Example of digital elaboration to assess the position of the MCL centre with respect to pupil from the images took with the slit lamp. The blue circle was the circular digital template which was aligned overlapping to the circumference of MCL. The red circles formed the pupil template (more circles were available to fit different pupil sizes) which was used to detect the pupil centre. The relative distance between the two centres was estimated from digital line (white line) joining them.

\section{Phase 3:}

In this phase the 44 topographical images ( 22 from right eyes and 22 from left eyes) acquired over the MCL by a videokeratography (ii, phase 1) were retrospectively evaluated to determine the position of the MCL centre with respect to the pupil centre.

The first evaluation was completely automatic and independent by observers who carried out the other manual evaluations (see below). Each topographical image was processed by a tangential algorithm and the software automatically identified the point of maximum curvature $\left(\mathrm{T}_{\max }\right)$ from the videokeratographic map. An operator overlaid the mouse cursor to that point on the map and the software automatically gave the coordinates of the point $(x$ and $y$ coordinates with respect to the pupil centre).

The second evaluation was performed manually by four different eye-care practitioners (ECPs, hereafter referred to as observers). Observer 1 (Obs1), and observer 2 (Obs2) were expert optometrists (more than 20 years of experience in practice), whereas observer 3 (Obs3) and observer (Obs4) were young optometrists (less than 5 years of experience in practice). In this 
way the effect of clinical experience in MCL centration assessment was explored. Each observer was asked to independently determine the centre of MCL operating on the topographical acquisitions with the following procedure.

The topographical files had been prepared in a database removing any information about the subject in order to prevent any possible memory bias. The order of the files (from 1 to 22 ) to analysed was randomly assigned to each observer. Each observer had to open the file and analysed in turn right eye or left eye in a random order. Once each topographical image of each file was open (right eye or left eye), the observer had to process it with three different algorithms and scale in a random order: tangential algorithm with absolute scale $\left(\mathrm{T}_{\mathrm{abs}}\right)$, tangential algorithm with adjustable scale with a step of $0.30 \mathrm{~mm}\left(\mathrm{~T}_{0.30}\right)$, and tangential algorithm with adjustable scale with a step of $0.20 \mathrm{~mm}\left(\mathrm{~T}_{0.20}\right)$ (Figure 3). Tangential algorithm was chosen since it allows to highlight more clearly localised topographical variations.

Once each single topographical image was processed, with a certain algorithm and scale, and the topographical map was displayed in a full-screen modality, a transparent sheet in acetate with concentric circles (template) to better identify the different zones of the MCL (Figure 4a) was overlaid on the map by the operator to detect the position of the multifocal CL centre (Figure 4b). Once its position was estimated, the mouse' cursor was positioned on this point (Figure 4c) and its $\mathrm{x}$ and $\mathrm{y}$ coordinates with respect to pupil centre were determined using topographic software (Figure 4d). The observer repeated the assessment other two times with 15- and 30-days delay but they were masked to on the previous reading/s during the following measurements.

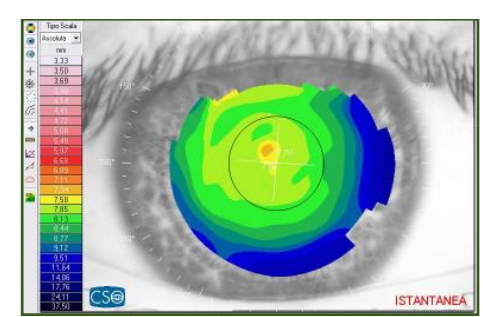

a) $T_{\text {abs }}$



b) $T_{0.3}$

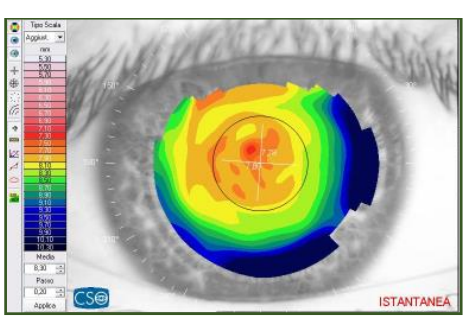

c) $T_{0.2}$

Figure 3. An example of the three different topographical outputs to determine the MCLs position. a: tangential algorithm with absolute scale $\left(\mathrm{T}_{\mathrm{abs}}\right)$. b: tangential algorithm with adjustable scale with a step of $0.30 \mathrm{~mm}\left(\mathrm{~T}_{0.30}\right)$. c: tangential algorithm with adjustable scale 
with a step of $0.20 \mathrm{~mm}\left(\mathrm{~T}_{0.20}\right)$. The small hyper-refractive central area of this specific CL is visible in the three maps.
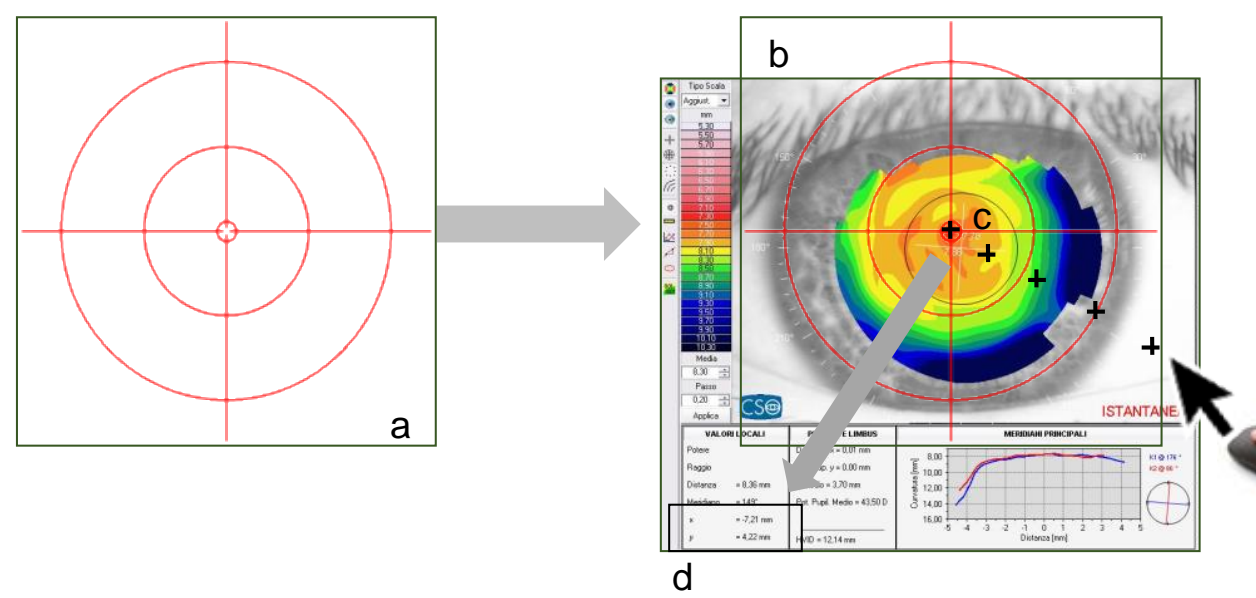

Figure 4. Example of the procedure to assess the $\mathrm{x}$ and $\mathrm{y}$ coordinates of the MCL centre with respect to pupil starting from topographical map displayed in a full-screen modality. The transparent sheet in acetate (a) was formed by a small circle in the centre to identify the small hyper-refractive central area of the specific CL used while the largest centre $(10 \mathrm{~mm})$ could be used to detect the optical zone. Once the template had been overlaid on the topographical map (b) the operator brought the mouse cursor on the centre of the template (c) and then the coordinates of the cursor (coincident with the centre of the lens) were read on the specific box of the software (d).

\section{Data Analysis}

The Kolmogorov-Smirnov test was used to evaluate the results for a normal distribution of data of $\mathrm{x}$ and $\mathrm{y}$ coordinates with respect to pupil centre. A paired Student's t-test was used to test the hypothesis that measure averages with two different procedures (SL versus each topographical procedure that is the average of the four ECPs) were significantly different. Person correlation coefficient (r) evaluated relationship between SL measures and topographical measures $\left(\mathrm{T}_{\max }, \mathrm{T}_{\mathrm{abs}}, \mathrm{T}_{0.30}\right.$ and $\mathrm{T}_{0.20}$ calculated as the mean of all measures determined by the four ECPs). A Bland-Altman plot was used to assess the difference in measurement of decentration ( $x$ and y coordinates separately) between SL assessment and the mean among the four ECPs of each topographical assessment $\left(T_{\max }, T_{a b s}, T_{0.30}\right.$ and $\left.T_{0.20}\right)$ as a 
function of the decentration values (mean between SL assessment and the mean among the four ECPs of each topographical assessment).

Furthermore, in order to find out if the 4 topographic assessment procedures to detect the MCL centration ( $\mathrm{T}_{\max }, \mathrm{T}_{\mathrm{abs}}, \mathrm{T}_{0.3}$, and $\left.\mathrm{T}_{0.2}\right)$ were interchangeable, a one-way Anova for repeated measure was performed.

Intraclass correlation coefficient (ICC) was used to investigate the inter and intra-operator reliability, using a 1-way random-effect model assuming a single measurement (McGraw and Wong 1996). In the case of inter-operator reliability ICC was worked out on the four measures obtained from the four different observers for the same topographical algorithm/scale method. For intra-operator reliability ICC was calculated, for each observer, on the three measures obtained with the same topographical algorithm/scale (Tabs, $\mathrm{T}_{0.3}$, and $\mathrm{T}_{0.2}$ ). According to Landis and Koch (1977), reliability was considered slight if ICC was comprised between 0.01 to 0.20 , fair if ICC was comprised between 0.21 and 0.40 , moderate if ICC was comprised between 0.41 to 0.60 , substantial if ICC was comprised between 0.61 and 0.80 , and finally excellent if ICC was more than 0.80 .

To further explore intra-operator reliability, a one-way Anova for repeated measure was used to evaluate difference between observers.

Data were analyzed using IBM $^{\odot}$ SPSS $^{\odot}$ Statistics v23.0 (SPSS Inc., Chicago, IL, USA).

\section{Results}

All the distributions of $x$ and $y$ coordinates with respect to pupil centre obtained for each eye with the slit lamp procedure and the topographical ones from the 4 different ECPs were normally distributed $(\mathrm{p}>0.5)$. The only variable which did not distribute normally $(\mathrm{p}<0.05)$ was the $\mathrm{y}$ coordinate determined by $\mathrm{T}_{\max }$ for the left eye; only for this case non-parametric statistics were used.

\section{Accuracy of Topographic procedures}

The values of MCLs centre coordinates $(\mathrm{x}, \mathrm{y})$ respected to pupil centre are reported in Table 2 as assessed by slit lamp (phase 2) and by the 4 modalities of topographic assessment (one automatic and three manuals; phase 3) for right eye and left eye, respectively. In the case of manual assessments ( $\mathrm{T}_{\mathrm{abs}}, \mathrm{T}_{0.30}$, and $\mathrm{T}_{0.20}$ ), the coordinates are the average of the measurements achieved by the 4 operators, (the measure of each one is the average of the three consecutive assessments). 
As it is possible to see from table 2, when the "gold standard" i.e. the slit lamp evaluation (SL) is considered, MCLs appear decentered temporally (negative $\mathrm{x}$ values for right eye and positive $\mathrm{x}$ value for left eye) and inferiorly (negative $\mathrm{y}$ values in both eyes) in both eyes.

For the right eye all the topographic methods estimated consistently a more temporal and superior (positive y-coordinate) position of MCLs with respect to SL assessment. The difference between measurement of MCL centration performed with $\mathrm{T}_{\max }$ and SL was significantly different both for $\mathrm{x}$ and y coordinates, paired $\mathrm{t}$ test $=2.29(\mathrm{p}=0.03)$ and paired $\mathrm{t}$ test $=-2.33(p=0.03)$, respectively. No difference between measurement of MCL centration performed by $\mathrm{T}_{\mathrm{abs}}$ (mean of 4 operators) and SL was found for $\mathrm{x}$ coordinate (paired t test $=$ $1.80 ; \mathrm{p}=0.09$ ), but significant difference was found for $\mathrm{y}$ coordinates (paired t test $=-2.24$; $\mathrm{p}=0.04$ ). The difference between measurement of MCL centration performed by $\mathrm{T}_{0.30}$ (mean of 4 operators) and SL was significantly different both for $\mathrm{x}$ and $\mathrm{y}$ coordinates, paired $\mathrm{t}$ test $=2.26$ $(\mathrm{p}=0.04)$ and paired t test $=-2.24(\mathrm{p}=0.04)$, respectively. The difference between measurement of CL centration performed by $\mathrm{T}_{0.20}$ (mean of 4 operators) and SL was significantly different both for $\mathrm{x}$ coordinates and y coordinates, paired $\mathrm{t}$ test $=2.25(\mathrm{p}=0.04)$ and paired $\mathrm{t}$ test $=-2.19$ $(\mathrm{p}=0.04)$, respectively.

For the left eyes all the topographic methods consistently estimated a superior position of MCLs with respect to SL assessment, but the differences were not significantly different; paired t test $\quad-1.79(p=0.09),-2.01(p=0.06),-1.80(p=0.09)$, and $-1.73(p=0.10)$ for $T_{\max }$, $\mathrm{T}_{\mathrm{abs}}, \mathrm{T}_{0.30}$, and $\mathrm{T}_{0.20,}$, respectively.

In terms of horizontal position, $\mathrm{T}_{\max }$ estimated a more temporal position with respect to $\mathrm{SL}$ while a more nasally position was estimate by both $\mathrm{T}_{\mathrm{abs}}, \mathrm{T}_{0.30}$ and $\mathrm{T}_{0.20}$. However, no difference reached significance; paired t test -1.07; $(p=0.29), 0.67(p=0.51), 0.70(p=0.50)$ and $0.45(\mathrm{p}=0.66)$ for $\mathrm{T}_{\max }, \mathrm{T}_{\mathrm{abs}}, \mathrm{T}_{0.30}$ and $\mathrm{T}_{0.20}$, respectively. 
Table 2: MCL centre coordinates (x,y) respected to pupil centre according the 5 different types of optical centre way of assessment $\left(\mathrm{S}, \mathrm{T}_{\max }, \mathrm{T}_{\mathrm{abs}}, \mathrm{T}_{0.3}\right.$ and $\left.\mathrm{T}_{0.2}\right) . \mathrm{T}_{\mathrm{abs}}, \mathrm{T}_{0.30}$, and $\mathrm{T}_{0.20}$ values represent the average of the values taken by the four different operators. Paired comparison (t-test) significance between each topographic assessment of a single coordinate and SL assessment are reported with an asterisk, at the level $\mathrm{p}<0.05$.

\begin{tabular}{|c|c|c|c|c|c|c|c|c|c|c|}
\hline \multicolumn{11}{|c|}{ Right Eye } \\
\hline $\begin{array}{l}\text { Type of MCL optical } \\
\text { centre assessment }\end{array}$ & \multicolumn{2}{|c|}{ SL } & \multicolumn{2}{|c|}{$T_{\max }$} & \multicolumn{2}{|c|}{$\mathrm{T}_{\mathrm{abs}}$} & \multicolumn{2}{|c|}{ To.3 } & \multicolumn{2}{|c|}{$\mathrm{T}_{0.2}$} \\
\hline Coordinate & $x$ & $y$ & $x$ & $y$ & $x$ & $y$ & $x$ & $y$ & $x$ & $y$ \\
\hline Mean (mm) & -0.11 & -0.18 & $-0.33^{*}$ & $0.18^{*}$ & -0.24 & $0.01 *$ & $-0.26 *$ & $0.01 *$ & $-0.27 *$ & $0.01 *$ \\
\hline $\mathrm{SD}(\mathrm{mm})$ & 0.24 & 0.43 & 0.39 & 0.62 & 0.32 & 0.30 & 0.30 & 0.34 & 0.31 & 0.35 \\
\hline $\operatorname{Max}(\mathrm{mm})$ & 0.46 & 0.56 & 0.33 & 1.49 & 0.27 & 0.49 & 0.23 & 0.86 & 0.26 & 0.90 \\
\hline $\operatorname{Min}(\mathrm{mm})$ & -0.50 & -1.08 & -0.95 & -0.72 & -0.87 & -0.65 & -0.88 & -0.63 & -0.88 & -0.51 \\
\hline \multicolumn{11}{|c|}{ Left Eye } \\
\hline $\begin{array}{l}\text { Type of MCL optical } \\
\text { centre assessment }\end{array}$ & \multicolumn{2}{|c|}{$\mathrm{SL}$} & \multicolumn{2}{|c|}{$T_{\max }$} & \multicolumn{2}{|c|}{$\mathrm{T}_{\mathrm{abs}}$} & \multicolumn{2}{|c|}{$T_{0.3}$} & \multicolumn{2}{|c|}{$\mathrm{T}_{0.2}$} \\
\hline Coordinate & $x$ & $y$ & $x$ & $y$ & $x$ & $y$ & $x$ & $\mathrm{y}$ & $x$ & $\bar{Y}$ \\
\hline Mean (mm) & 0.34 & -0.10 & 0.47 & 0.21 & 0.29 & 0.06 & 0.29 & 0.04 & 0.31 & 0.03 \\
\hline $\mathrm{SD}(\mathrm{mm})$ & 0.15 & 0.32 & 0.62 & 0.73 & 0.36 & 0.27 & 0.35 & 0.27 & 0.33 & 0.27 \\
\hline $\operatorname{Max}(\mathrm{mm})$ & 0.54 & 0.43 & 1.80 & 2.11 & 1.09 & 0.46 & 1.11 & 0.44 & 1.10 & 0.45 \\
\hline $\operatorname{Min}(\mathrm{mm})$ & 0.09 & -0.71 & -0.84 & -0.80 & -0.33 & -0.50 & -0.38 & -0.51 & -0.30 & -0.51 \\
\hline
\end{tabular}

In table 3, correlation coefficients ( $\mathrm{r}$ ) of the relations between all procedures to assess MCLs position are reported (for manual topographical measurements the values are the average of the four ECPs). For what concerns x coordinate, SL does not correlate with the topographical measures both for right eye and the left eye, whereas significant correlation is found among all the topographical measures $\left(\mathrm{T}_{\max }, \mathrm{T}_{\mathrm{abs}}, \mathrm{T}_{0.30}\right.$ and $\left.\mathrm{T}_{0.20}\right)$. Concerning $\mathrm{y}$ coordinate, in the right eye SL assessment of MCL correlates significantly with $\mathrm{T}_{\mathrm{abs}}, \mathrm{T}_{0.3}$, and $\mathrm{T}_{0.2}$, but not with $\mathrm{T}_{\max }$, whereas again all correlations among all the topographical measures $\left(\mathrm{T}_{\max }, \mathrm{T}_{\mathrm{abs}}, \mathrm{T}_{0.30}\right.$, and $\mathrm{T}_{0.20}$ ) resulted significant. For the y coordinate on the left eye, correlations resulted significant among all the topographical measures $\left(\mathrm{T}_{\max }, \mathrm{T}_{\mathrm{abs}}, \mathrm{T}_{0.30}\right.$, and $\left.\mathrm{T}_{0.20}\right)$, but not between SL and the remaining procedures.

The Bland-Altman plots, for the paired comparison between the centration measurement with SL and the 4 modalities of topographic assessment $\left(\mathrm{T}_{\mathrm{Max}}, \mathrm{T}_{\mathrm{abs}}, \mathrm{T}_{0.30}\right.$, and $\mathrm{T}_{0.20}$ ), are shown in Figure 4 and Figure 5 for right eye and left eye, respectively.

The Bland-Altman plots for the comparison between SL and $\mathrm{T}_{\mathrm{Max}}$ show that the difference between the two methods became significantly more positive (position more shift towards the right for x coordinate and upper for y coordinate) moving to more positive position of the 
MCL. More precisely coefficient of correlation resulted $0.46(\mathrm{p}=0.03), 0.90(\mathrm{p}<0.001), 0.67$ $(\mathrm{p}=0.01)$ for $\mathrm{x}$ coordinate of right eye (Figure 5a), x coordinate of left eye (Figure 6a), and y coordinate of left eye (Figure 6b) respectively (proportional bias).

The Bland-Altman plots for the comparison between $\mathrm{SL}$ and $\mathrm{T}_{\mathrm{Max}}, \mathrm{T}_{0.3}$ and $\mathrm{T}_{02}$ show a proportional bias only for x coordinate evaluation in left eye (Figure $6 \mathrm{c}, 6 \mathrm{e}$ and $6 \mathrm{~g}$ )

With a coefficient of correlation of $0.73(\mathrm{p}<0.001), 0.72(\mathrm{p}<0.001)$, and $0.69(\mathrm{p}<0.001)$ respectively.

The 4 topographic assessment procedures to detect the multifocal CL centration $\left(T_{\max }, T_{a b s}\right.$, $\mathrm{T}_{0.30}$ and $\mathrm{T}_{0.20}$ ) resulted almost equivalent in detecting the centre coordinates. For the right eye the one-way Anova didn't show any difference among 4 procedures both for $\mathrm{x}$ and $\mathrm{y}$ coordinates; $F_{3,21}=1.45(p=0.24)$ and $F_{3,21}=2.17(p=0.10)$ respectively. For the left eye the one-way Anova didn't show any difference among 4 procedures for y coordinate (one-way Anova $\mathrm{F}_{3,21}=1.60 ; \mathrm{p}=0.20$ ) but a significant difference was found for $\mathrm{x}$ coordinate (one-way Anova $\mathrm{F}_{3,21}=2.90 ; \mathrm{p}=0.042$ ).

Table 3: Shows a correlation matrix (Pearson correlation coefficients) for $\mathrm{x}$ and $\mathrm{y}$ coordinates of MCL decentration determined by SL and the four topographical procedures for both eyes.

\begin{tabular}{|c|c|c|c|c|c|c|c|c|c|c|c|}
\hline \multicolumn{6}{|c|}{ Right Eye } & \multicolumn{6}{|c|}{ Left Eye } \\
\hline & SL_ $x$ & $\mathrm{~T}_{\max _{x}} \mathrm{X}$ & $\mathrm{T}_{\text {abs_ }} \mathrm{x}$ & $\mathrm{T}_{0.3} \mathrm{x}$ & $\mathrm{T}_{0.2} \mathrm{x}$ & & SL_x & $\mathrm{T}_{\max _{\mathrm{X}} \mathrm{X}}$ & $\mathrm{T}_{\text {abs_}} \mathrm{x}$ & $\mathrm{T}_{0.3 \_} \mathrm{x}$ & $\mathrm{T}_{0.2 \mathrm{X}} \mathrm{x}$ \\
\hline SL $x$ & 1 & & & & & SL $x$ & 1 & & & & \\
\hline $\mathrm{T}_{\max } \mathrm{x}$ & 0.06 & 1 & & & & Tmax $\mathrm{x}$ & 0.39 & 1 & & & \\
\hline$T_{\text {abs_ }} \mathrm{X}$ & 0.28 & $.71 * *$ & 1 & & & Tabs_x & 0.33 & $.67 * *$ & 1 & & \\
\hline $\mathrm{T}_{0.3 \_\mathrm{X}}$ & 0.33 & $.70 * *$ & $.99 * *$ & 1 & & T0.3_x & 0.34 & $.65 * *$ & $.99 * *$ & 1 & \\
\hline $\mathrm{T}_{0.2 \_\mathrm{X}}$ & 0.31 & $.70^{* *}$ & $.99 * *$ & $.99 * *$ & 1 & $\mathrm{~T} 0.2 \_\mathrm{x}$ & 0.33 & $.62 * *$ & $.99 * *$ & $.99 * *$ & 1 \\
\hline & SL_y & Tmax_y & Tabs_y & T0.3@y & T0.2_y & & SL_y & $\mathrm{T}_{\max \_\mathrm{y}}$ & $\mathrm{T}_{\mathrm{abs} \_\mathrm{y}}$ & $\mathrm{T}_{0.3 \_\mathrm{y}}$ & $\mathrm{T}_{0.2 \_\mathrm{y}}$ \\
\hline SL y & 1 & & & & & SL y & 1 & & & & \\
\hline $\mathrm{T}_{\max \_\mathrm{y}}$ & 0.11 & 1 & & & & $\mathrm{~T}_{\max \_\mathrm{y}}$ & $0.24 \#$ & 1 & & & \\
\hline $\mathrm{T}_{\text {abs_} \_\mathrm{y}}$ & $.48^{*}$ & $.56 * *$ & 1 & & & $\mathrm{~T}_{\text {abs_y }} \mathrm{y}$ & 0.28 & $.58^{* *}$ & 1 & & \\
\hline $\mathrm{T}_{0.3 \mathrm{y}} \mathrm{y}$ & $.49 *$ & $.56 * *$ & $.96 * *$ & 1 & & $\mathrm{~T}_{0.3 \mathrm{y}} \mathrm{y}$ & 0.27 & $.59 * *$ & $.99 * *$ & 1 & \\
\hline $\mathrm{T}_{0.2 \_\mathrm{y}}$ & $.45^{*}$ & $.51 *$ & $.95 * *$ & $.99 * *$ & 1 & $\mathrm{~T}_{0.2 \_\mathrm{y}}$ & 0.30 & $.63 * *$ & $.98 * *$ & $.97 * *$ & 1 \\
\hline
\end{tabular}

$* P<0.05$ level (2-tailed). ** $p<0.01$ level (2-tailed). \# Spearman correlation 


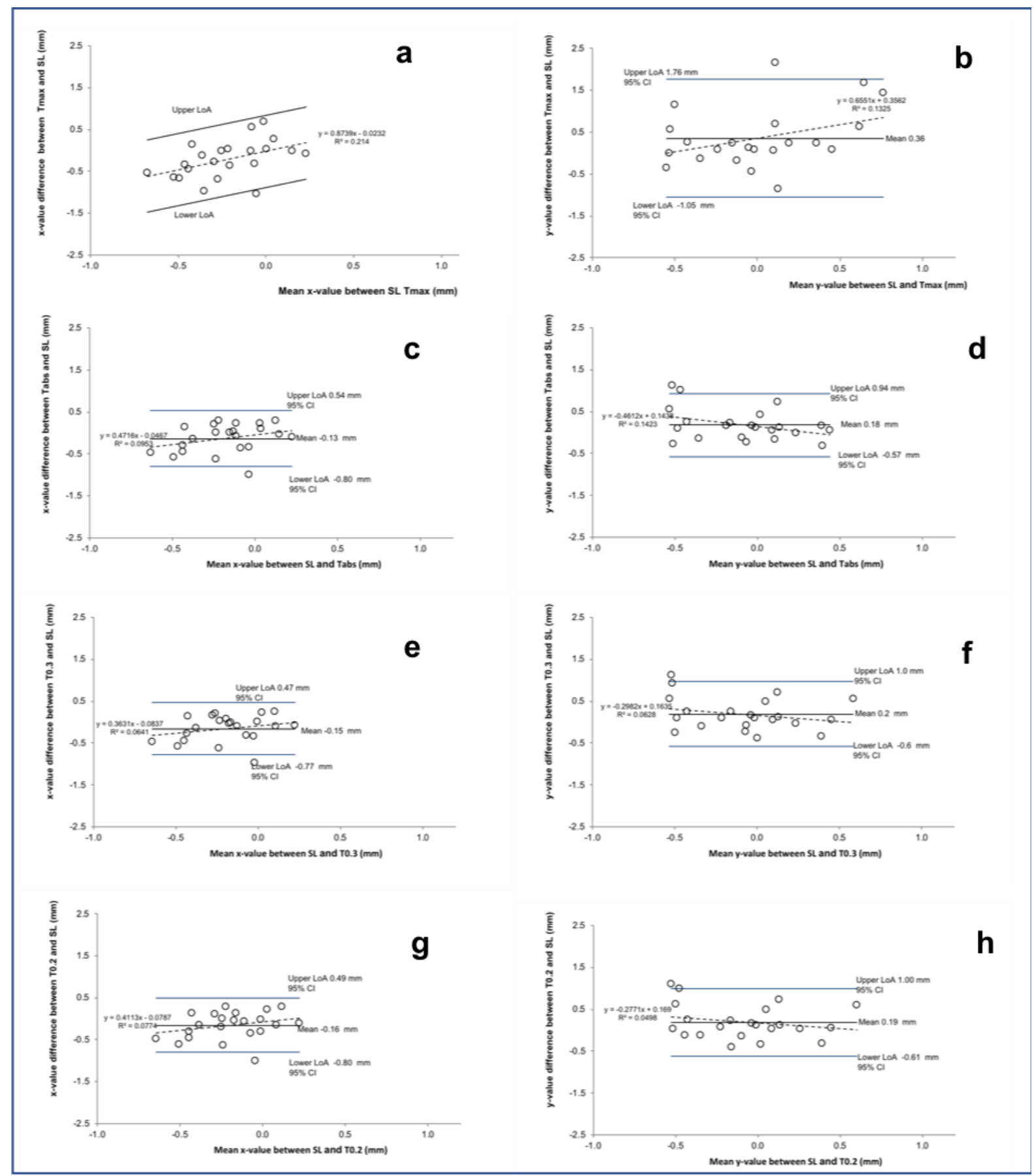

Figure 5. Bland-Altman plots of the differences between SL and each topographical methods in $x$ and $y$ coordinates assessment of MCL centre position in right eye plotted against the mean of the two measures compared. Limits of Agreement are calculated as mean difference $\pm 1.96 \mathrm{SD}$ of differences, $\mathrm{CI}$ at $95 \%$ calculated as Bland and Altman [18]. 


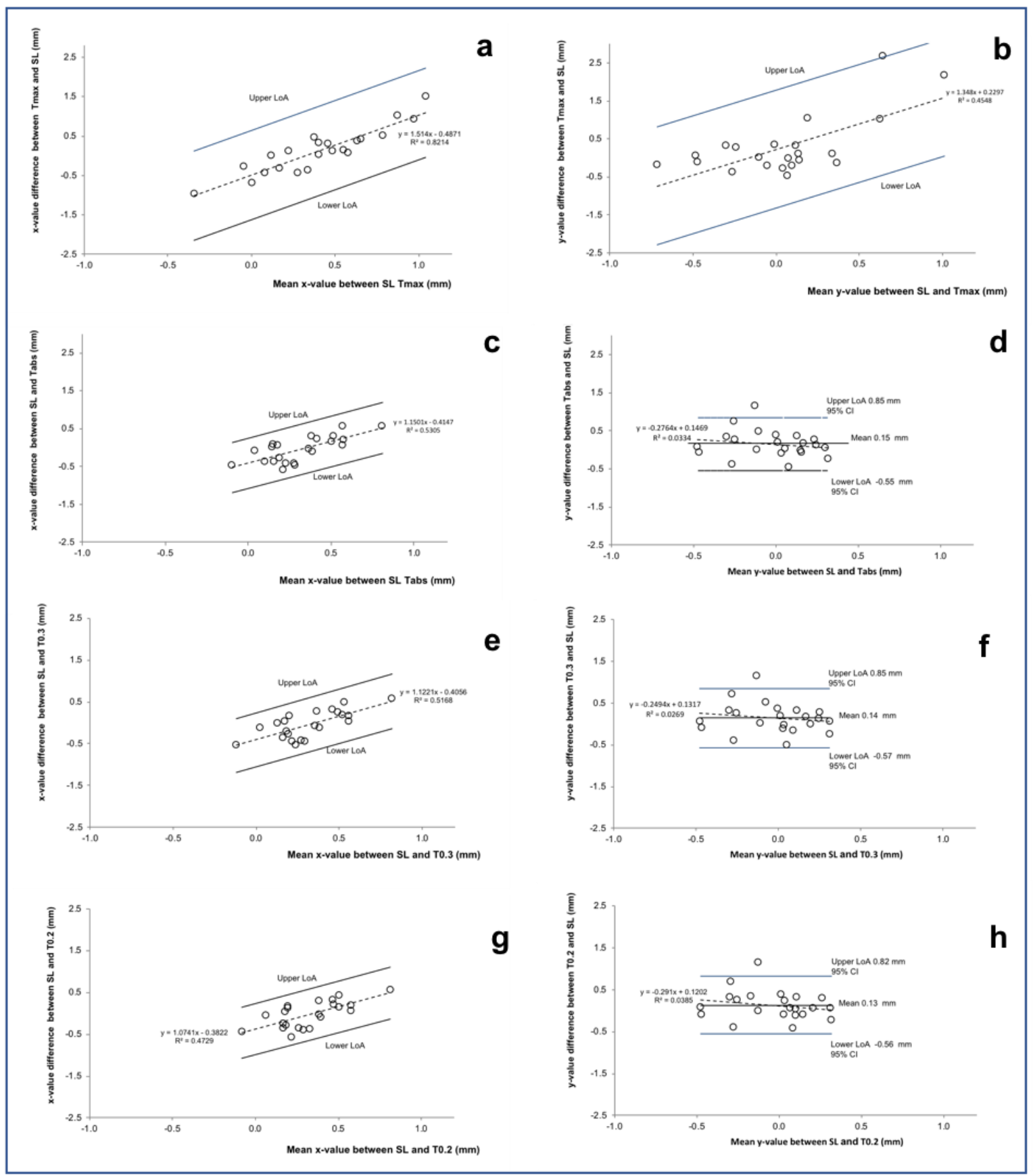

Figure 6. Bland-Altman plots of the differences between SL and each topographical methods in $x$ and $y$ coordinates assessment of MCL centre position in left eye plotted against the mean of the two measures compared. Limits of Agreement are calculated as mean difference $\pm 1.96 \mathrm{SD}$ of differences, CI at 95\% calculated as Bland and Altman [18]. 


\section{Inter-operator reliability}

Mean \pm SD of $x$ and $y$ coordinates achieved from the 4 ECPs with the 3 modalities of MCL assessment of centration with Topography $\left(\mathrm{T}_{\mathrm{abs}}, \mathrm{T}_{0.3}\right.$ and $\mathrm{T}_{0.2}$ ) are reported in table 4.

Excellent inter-observer reliability (ICC > 0.80) was found for the assessment of $\mathrm{x}$ coordinate of right MCL with $\mathrm{T}_{\mathrm{abs}}, \mathrm{T}_{0.3}$ and $\mathrm{T}_{0.2}$ and for $\mathrm{y}$ coordinate assessment of right MCL with $\mathrm{T}_{0.2}$. Substantial inter-observer reliability (ICC between 0.61 and 0.80 ) was found for the assessment of $\mathrm{y}$ coordinate of right MCL with $\mathrm{T}_{\mathrm{abs}}$, and $\mathrm{T}_{0.3}$ and for $\mathrm{x}$ coordinate assessment of left MCL with $\mathrm{T}_{\mathrm{abs}}, \mathrm{T}_{0.3}$ and $\mathrm{T}_{0.2}$.

Moderate inter-observer reliability (ICC between 0.41 and 0.60 ) was found for the assessment of y coordinate of left MCL with $\mathrm{T}_{\mathrm{abs}}, \mathrm{T}_{0.3}$ and $\mathrm{T}_{0.2}$.

Among 4 ECPs one-way Anovas for repeated measures showed no differences in almost all the condition that is proof of a good Inter-operator reliability. Only in right eye for $\mathrm{x}$ coordinate achieved with $\mathrm{T}_{\mathrm{abs}}$ and $\mathrm{T}_{0.3}$, means resulted significantly different $\left(\mathrm{F}_{3,21}=4.01\right.$; $\mathrm{p}=0.01$ and $\mathrm{F}_{3,21}=2.70 ; \mathrm{p}=0.05$ respectively). In both cases pairwise comparison ( $\mathrm{t}$ test) showed that ECP_2 resulted different from ECP_1, ECP_3 and ECP_4 (all p<0.05)

Table 4: mean \pm SD of MCL centre coordinates ( $x$ and $y$ ) on the right and left eyes achieved from the four observers with the three manual modalities of MCL assessment of centration with Topography ( $\mathrm{T}_{\mathrm{abs}}, \mathrm{T}_{0.3}$, and $\mathrm{T}_{0.2}$ ). Intraclass correlation coefficient (ICC) (single measures, with $95 \% \mathrm{CI}$ ) for each kind of assessment for the four observers are reported. One-way Anovas for repeated measure results ( $\mathrm{F}$ and significance) are reported for each kind of assessment among the four observers.

\begin{tabular}{|c|c|c|c|c|c|c|}
\hline \multicolumn{7}{|c|}{ Right eye } \\
\hline & \multicolumn{2}{|c|}{ Tabs } & \multicolumn{2}{|c|}{$\mathrm{T}_{0.3}$} & \multicolumn{2}{|c|}{ To.2 } \\
\hline & $\mathrm{X}$ & $y$ & $x$ & $y$ & $x$ & $y$ \\
\hline Obs1 & $-0.22 \pm 0.33 \mathrm{~mm}$ & $0.04 \pm 0.32 \mathrm{~mm}$ & $-0.26 \pm 0.31 \mathrm{~mm}$ & $0.05 \pm 0.38 \mathrm{~mm}$ & $-0.26 \pm 0.33 \mathrm{~mm}$ & $0.04 \pm 0.36 \mathrm{~mm}$ \\
\hline Obs2 & $-0.18 \pm 0.37 \mathrm{~mm}$ & $-0.03 \pm 0.34 \mathrm{~mm}$ & $-0.21 \pm 0.34 \mathrm{~mm}$ & $-0.06 \pm 0.38 \mathrm{~mm}$ & $-0.23 \pm 0.33 \mathrm{~mm}$ & $-0.03 \pm 0.38 \mathrm{~mm}$ \\
\hline Obs3 & $-0.27 \pm 0.32 \mathrm{~mm}$ & $0.01 \pm 0.32 \mathrm{~mm}$ & $-0.30 \pm 0.31 \mathrm{~mm}$ & $0.02 \pm 0.37 \mathrm{~mm}$ & $-0.30 \pm 0.32 \mathrm{~mm}$ & $0.03 \pm 0.38 \mathrm{~mm}$ \\
\hline Obs4 & $-0.29 \pm 0.33 \mathrm{~mm}$ & $0.00 \pm 0.33 \mathrm{~mm}$ & $-0.29 \pm 0.32 \mathrm{~mm}$ & $0.02 \pm 0.34 \mathrm{~mm}$ & $-0.29 \pm 0.33 \mathrm{~mm}$ & $0.01 \pm 0.36 \mathrm{~mm}$ \\
\hline ICC & 0.87 & 0.79 & 0.86 & 0.80 & 0.86 & 0.83 \\
\hline $\begin{array}{l}\text { Repeated } \\
\text { Measure Anova }\end{array}$ & $\begin{array}{c}F_{3,21}=4.01 \\
\mathbf{p}=\mathbf{0 . 0 1}\end{array}$ & $\begin{array}{c}\mathrm{F}_{3,21}=0.77 \\
\mathrm{p}=0.51\end{array}$ & $\begin{array}{c}\mathrm{F}_{3,21}=2.70 \\
\mathrm{p}=\mathbf{0 . 0 5}\end{array}$ & $\begin{array}{c}F_{3,21}=1.66 \\
p=0.18\end{array}$ & $\begin{array}{c}\mathrm{F}_{3,21}=1.48 \\
\mathrm{p}=0.23\end{array}$ & $\begin{array}{c}\mathrm{F}_{3,21}=0.89 \\
\mathrm{p}=0.45\end{array}$ \\
\hline \multicolumn{7}{|c|}{ Left eye } \\
\hline & \multicolumn{2}{|c|}{ Tabs } & \multicolumn{2}{|c|}{$\mathrm{T}_{0.3}$} & \multicolumn{2}{|c|}{$\mathrm{T}_{0.2}$} \\
\hline & $\mathrm{X}$ & $\mathrm{y}$ & $X$ & $\mathrm{y}$ & $X$ & $\mathrm{y}$ \\
\hline Obs1 & $0.28 \pm 0.45 \mathrm{~mm}$ & $0.13 \pm 0.35 \mathrm{~mm}$ & $0.28 \pm 0.45 \mathrm{~mm}$ & $0.12 \pm 0.35 \mathrm{~mm}$ & $0.30 \pm 0.45 \mathrm{~mm}$ & $0.09 \pm 0.35 \mathrm{~mm}$ \\
\hline Obs2 & $0.25 \pm 0.35 \mathrm{~mm}$ & $0.00 \pm 0.32 \mathrm{~mm}$ & $0.25 \pm 0.35 \mathrm{~mm}$ & $-0.01 \pm 0.33 \mathrm{~mm}$ & $0.28 \pm 0.31 \mathrm{~mm}$ & $-0.03 \pm 0.33 \mathrm{~mm}$ \\
\hline Obs3 & $0.27 \pm 0.44 \mathrm{~mm}$ & $0.09 \pm 0.33 \mathrm{~mm}$ & $0.27 \pm 0.42 \mathrm{~mm}$ & $0.08 \pm 0.34 \mathrm{~mm}$ & $0.28 \pm 0.42 \mathrm{~mm}$ & $0.10 \pm 0.35 \mathrm{~mm}$ \\
\hline Obs4 & $0.38 \pm 0.40 \mathrm{~mm}$ & $0.00 \pm 0.37 \mathrm{~mm}$ & $0.38 \pm 0.38 \mathrm{~mm}$ & $-0.01 \pm 0.37 \mathrm{~mm}$ & $0.39 \pm 0.38 \mathrm{~mm}$ & $-0.03 \pm 0.34 \mathrm{~mm}$ \\
\hline ICC & 0.67 & 0.48 & 0.67 & 0.49 & 0.61 & 0.45 \\
\hline $\begin{array}{l}\text { Repeated } \\
\text { Measure Anova }\end{array}$ & $\begin{array}{c}\mathrm{F}_{3,21}=1.41 \\
\mathrm{p}=0.25\end{array}$ & $\begin{array}{c}\mathrm{F}_{3,21}=1.50 \\
\mathrm{p}=0.22\end{array}$ & $\begin{array}{c}\mathrm{F}_{3,21}=1.50 \\
\mathrm{p}=0.22\end{array}$ & $\begin{array}{c}F_{3,21}=1.47 \\
p=0.23\end{array}$ & $\begin{array}{c}\mathrm{F}_{3,21}=1.11 \\
\mathrm{p}=0.35\end{array}$ & $\begin{array}{c}F_{3,21}=1.82 \\
p=0.15\end{array}$ \\
\hline
\end{tabular}




\section{Intra-operator reliability}

ICCs calculated for each operator among the 3 readings (at time 0, after 15 days and after 30 days) achieved with the 3 modalities of CL assessment of centration with Topography ( $\mathrm{T}_{\mathrm{abs}}$, $\mathrm{T}_{0.3}$ and $\left.\mathrm{T}_{0.2}\right)$ for each coordinate $(x, y)$ and for each eye, are reported in table 5.

Excellent inter-observer reliability (ICC > 0.80) was found in Obs1 and Obs3 for all kind of measures and for Obs4 in all the measures apart the $y$ coordinates of left eye evaluated with $\mathrm{T}_{\mathrm{abs}}, \mathrm{T}_{0.3}$ and $\mathrm{T}_{0.2}$ in which reliability was in any case substantial (ICC between 0.72 and 0.75 ). In the case of Obs2, the results appeared more heterogeneous with ICC, and ranged from excellent values to moderate values, depending from the measures (Table 5).

Table 5: Intraclass correlation coefficients (single measures, with 95\% CI)

\begin{tabular}{|l|c|c|c|c|c|c|c|c|c|c|c|c|}
\hline & \multicolumn{4}{|c|}{$T_{\text {abs }}$} & \multicolumn{4}{c|}{$T_{0.3}$} & \multicolumn{4}{c|}{$T_{0.2}$} \\
\hline & Right eye & Left eye & \multicolumn{1}{c|}{ Right eye } & \multicolumn{2}{c|}{ Left eye } & \multicolumn{2}{c|}{ Right eye } & \multicolumn{2}{c|}{ Left eye } \\
\hline & $\mathrm{x}$ & $\mathrm{y}$ & $\mathrm{x}$ & $\mathrm{y}$ & $\mathrm{x}$ & $\mathrm{y}$ & $\mathrm{x}$ & $\mathrm{y}$ & $\mathrm{x}$ & $\mathrm{y}$ & $\mathrm{x}$ & $\mathrm{y}$ \\
\hline Obs1 & 0.97 & 0.94 & 0.96 & 0.98 & 0.97 & 0.98 & 0.96 & 0.97 & 0.97 & 0.77 & 0.95 & 0.78 \\
\hline Obs2 & 0.90 & 0.79 & 0.68 & 0.57 & 0.90 & 0.92 & 0.78 & 0.49 & 0.89 & 0.89 & 0.74 & 0.60 \\
\hline Obs3 & 0.96 & 0.92 & 0.91 & 0.95 & 0.95 & 0.94 & 0.92 & 0.94 & 0.96 & 0.90 & 0.92 & 0.95 \\
\hline Obs4 & 0.90 & 0.88 & 0.85 & 0.72 & 0.85 & 0.81 & 0.84 & 0.74 & 0.90 & 0.93 & 0.83 & 0.75 \\
\hline
\end{tabular}

\section{Discussion}

Despite the fact that mechanisms of perceptual and physiological adaptation to the modern strategies to correct presbyopia with CL such as simultaneous-imaging principle or monovision or even with multifocal intraocular lenses have been described (Woods et al, 2010; Zeri et al, 2017, Rosa et al. 2017, Zeri et al, 2018a, Zeri et al, 2018b), it remains a priority to optimise the optical functioning underneath these techniques (Charman, 2014, Bakaraju et al 2010; Nio et al 2002). The possibility to assess MCL centration is therefore of paramount importance to clinically understand and improve visual outcomes with this kind of devices (Woods et al, 1993).

In this study the accuracy and the inter- and intra-repeatability of a technique using corneal topography performed over a MCL to detect MCL centration have been investigated.

The accuracy of each single topographical assessment studied, to determine the MCL centre fitted, was explored by paired comparison with the gold standard (SL), correlations, and Bland Altman plots. The picture that came from these statistics is not perfectly homogeneous. 
Measures of MCL centration with all corneal topography assessments on the left eye appeared in good agreement if compared to SL assessment (all t-test not significant) (Table 2). This was not found in the case of right MCL where the differences were statistically significant for almost all the paired comparisons (Table 2). However, it should be noted that the largest error found, in terms of absolute value, was made with $\mathrm{T}_{\max }$ and resulted $0.22 \mathrm{~mm}$ ( $95 \% \mathrm{CI}-1.07$ to $0.87 \mathrm{~mm}$ ) and $0.36 \mathrm{~mm}(95 \% \mathrm{CI}-1.05$ to $1.4 \mathrm{~mm}$ ) for $\mathrm{x}$ and y coordinates, respectively. These average error values appear quite small looking at the power profiles of commercial aspheric MCL published in literature, where the variation in power in one third of $\mathrm{mm}$ (the maximum error found in this study) appears negligible especially in the central $6 / 8 \mathrm{~mm}$ of the optic zone (Monsálvez-Romín et al 2018, Plainis et al, 2013). However, the 95\% CI of error in centration is not so small and could be relevant for some MCLs in which the power profile, limited to same portions of optic zone, can change quickly and it depends on the amount of addition (high add MCLs presents sudden variation) as well as the MCL design (ring bifocal design i.e. concentric alternating near and far zone such as the one of Acuvue Bifocal; Vistakon, Inc., Jacksonville, FL, USA which have sudden variations) (Madrid-Costa et al, 2015; Wagner et al, 2015).

Concerning correlation analysis, a significant correlation between measures with SL and topographical assessments was found for $\mathrm{y}$ coordinates in right eye limited to $\mathrm{T}_{\mathrm{abs}}, \mathrm{T}_{0.3}$, and $\mathrm{T}_{0.2 \text {. }}$ All the rest of correlation analysis between $\mathrm{SL}$ and topographical assessment were not significant. When considering the Bland Altman plots, the topographical methods were more affected by a proportional bias; i.e.the more positive the MCL decentration the higher the difference between the two ways of assessment.. Also, Bland Altman plots for $\mathrm{T}_{\max }$ showed the largest distance between the upper and lower levels of 95\% CI (roughly $2 \mathrm{~mm}$ of differences) compared to the others algorithms plots.

Overall, it appears that the slightly less accurate topographical method for assessing MCL centration in comparison to the SL gold standard was the one based on $\mathrm{T}_{\max }$ algorithm. In fact, this method produced the highest absolute differences in detecting centre coordinates compare to SL (see Table 2), poor correlation with SL values, and a proportional bias in Bland Altman plots in three out of four comparisons ( $x$ coordinates right eye, $x$ coordinates left eye and $y$ coordinates right eye). In order to provide a possible explanation to this, it should be bear in mind that the $\mathrm{T}_{\max }$ algorithm was based on the assumption that the point of maximum curvature of the videokeratographical map was coincident with the MCL centre. The presence on the MCL surface of a tear agglomerate or an irregularity could be origin a point of steep curve which con be likely detected as the point of highest curvature. Indeed, 
this kind of algorithm was not suggested for the purpose of identification of CL position through over topography in the few papers that proposed or used this new method (Dave, 2015; Vincent \& Collins, 2019). The reason why in this study this algorithm was evaluated was it could be useful in assessing the centre of the MCL chose for the study, characterised by a small area of strong hyperprolature in the centre-near design.

The inter-repeatability of this new method proposed for MCL centration assessment resulted quite good. Differences among observers resulted significant only in $x$ coordinate evaluation of right eye with $\mathrm{T}_{\mathrm{abs}}$ and $\mathrm{T}_{0.3}$ (Table 4 ).

Also, the intra-repeatability of the method appeared extremely good and it is not possible to recognise a clear advantage of on algorithm in improving ICCs of the four observers. Moreover, looking at the ICCs of the different observers a clear advantage for more experienced observers cannot be detected. The lowest ICCs resulted in Obs2 limited to some algorithms used. It should be noted that although Obs2 had a long experience in practice (more than 30 years), he was the only one among the four that did not use routinely videokerathography in his practice. Maybe more than experience, the fact that may influence the reliability of the method could be the familiarity with the tool.

Several limitations of the present research should be considered. Firstly, the technique to assess CL centration has been used on a specific lens characterised by a small central area of hyperprolature that could be easier to detect with a finer algorithm to process topographical over-CL map, such as the $\mathrm{T}_{0.20}$, and less simple to visualised with a different algorithm, for example the $\mathrm{T}_{\mathrm{abs}}$ or the $\mathrm{T}_{0.30}$. So, the outcomes of this study cannot automatically be transferred to other MCL design in which the technique could reveal itself less or more accurate and reliable but depending by the kind of algorithm used. Moreover, the lenses were new and just fitted, so differences in CL centration and its assessment could be found in daily disposable MCLs at the end of the day or even more for reusable lenses after several days/weeks of wear. Indeed, deposition may influence lens centration and quality of the topography assessment. Another important factor to take into account, is the specific characteristic of the topography used. Placido-disc based topographers varies for their shape, the size of the disc, the number of the rings and the final working distance that also depends on corneal curvature under examination (Dave, 1998). These differences could change results in terms of accuracy and repeatability of the procedure.

Another potential bias to be considered, is the fact the lens used for the study was a single power lens (plano). To evaluate the effect of a wider CL power range on the accuracy of the procedure, a specific experiment should be set up. However, a plano lens might have not an 
easy detectable optic zone with respect to a lens with a spherical power. The presence of a much clearer optical zone in CL with different powers could help in contributing to the detection of the centration of the lens making the procedure even better.

A further aspect to consider is about the study sample which age ranged between 21 and 27 years. MCLs are becoming more popular for young people in order to prevent myopia progression and this represented one reason to study this age range. However, a certain level of prudence should be kept in transferring the present results to a presbyopic population for several reasons potentially interfering with lens centration such as ocular surface irregularity, less stable tear film etc.

To conclude, the possibility to assess MCL centration by performing a topography over the lens showed to be an acceptable method in terms of accuracy, for the MCL design investigated in this study. The techniques should be expandable to other MCL designs to see if this remains true for other MCL designs. Furthermore, inter and intra-practitioner reliability showed by manual procedures appeared good and not affected by operator experience.

Considering that the slit lamp assessment of MCL centration does not allow an easy detection of CL centre because a certain work on the digital image is required in any case, the videokeratograpy assessment of MCL centration could represent a suitable tool in clinical practice that in a near future could be incorporated in new releases of topographer's software.

\section{Conflicts of Interest Disclosure}

The authors report no conflicts of interest and have no proprietary interest in any of the materials mentioned in this article.

\section{Funding Sources Disclosure}

During the period of the research, Dr Fabrizio Zeri was funded with the support of the European Union under a Marie Curie Intra-European Fellowship for Career Development (FP7), Grant Agreement number 622786.

\section{Acknowledgements}

We wish to thank Safilens for providing the CLs used in the experiment. 


\section{References}

[1] Lamb J, Bowden T. 1 The History of Contact Lenses. Contact Lenses E-Book. 2018 Nov 29:2. (REF Phillips Speedwell)

[2] White P. Contact Lens and Solutions Summary (2018). Available at: https://www.clspectrum.com/class

[3] Charman,W.N. Developments in the correction of presbyopia I: spectacle and contact lenses. Ophthalmic Physiol.Opt.34,8-29(2014).

[4] Plainis S, Atchison DA, Charman WN. Power profiles of multifocal contact lenses and their interpretation. Optom Vis Sci 2013;90(10):1066-77.

[5] Pérez- Prados R, Piñero DP, Pérez- Cambrodí RJ, Madrid- Costa D. Soft multifocal simultaneous image contact lenses: a review. Clinical and Experimental Optometry. 2017 Mar;100(2):107-27.

[6] Bakaraju RC, Ehrmann K, Papas EB, Ho A. Depth-of-focus and its association with the spherical aberration sign. A ray-tracing analysis. Journal of optometry. 2010 Jan 1;3(1):51-9.

[7] Y. K. Nio*, , N. M. Jansonius*, , V. Fidlerà, E. Geraghty§, S. Norrby§ and A. C.

Kooijman*, ,- Spherical and irregular aberrations are important for the optimal performance of the human eye Ophthal. Physiol. Opt. 200222 103-112

[8] Diec J, Tilia D, Naduvilath T, et al. Predicting short-term performance of multifocal contact lenses. Eye Contact Lens 2017;43:340-345.

[9] Zeri F, Di Censi M, Livi S, Ercoli A, Naroo SA. Factors That Influence the Success of Contact Lens Fitting in Presbyopes: A Multicentric Survey. Eye \& Contact Lens. 2019 Apr 15 .

[10] Sankaridurg P, Holden B, Smith E, Naduvilath T, Chen X, de la Jara PL, Martinez A, Kwan J, Ho A, Frick K, Ge J. Decrease in rate of myopia progression with a contact lens designed to reduce relative peripheral hyperopia: one-year results. Investigative ophthalmology \& visual science. 2011 Dec 1;52(13):9362-7.

[11] Walline JJ, Greiner KL, McVey ME, Jones-Jordan LA. Multifocal contact lens myopia control. Optometry and Vision Science. 2013 Nov 1;90(11):1207-14.

[12] Sankaridurg PR, Holden BA. Practical applications to modify and control the development of ametropia. Eye. 2014 Feb;28(2):134.

[13] Woods, R.L., Saunders, J.E. and Port, M.J., 1993. Optical performance of decentered bifocal contact lenses. Optometry and vision science, 70(3), pp.171-184.

[14] Dave T. Understanding multifocals and getting them to work. Optician 2015; 249: 1217. 
[15] Applegate RA, Thibos LN, Bradley A, Marcos S, Roorda A, Salmon TO, Atchison DA. Reference axis selection: subcommittee report of the OSA Working Group to establish standards for measurement and reporting of optical aberrations of the eye. Journal of Refractive Surgery. 2000 Sep 1;16(5):S656-8.

[16] Mosquera SA, Verma S, McAlinden C. Centration axis in refractive surgery. Eye and Vision. 2015 Dec;2(1):4.

[17] Wolffsohn James S, Hunt Olivia A, Basra AK. Simplified recording of soft contact lens fit. Contact Lens \& Anterior Eye 32 (2009) 37-42

[18] Lampa M, et al. Assessing multifocal soft contact lens centration with the aid of corneal topography. Poster presented at 2012 Global Specialty Lens Symposium, January 26-29, 2012; Las Vegas, NV.

[19] Miller JR, Brujic M Minimize follow-up for multifocal contacts: do you hesitate to offer multifocal contact lenses to your presbyopes? Review of Optometry; 2012 149: 48-52.

[20] Stephen J. Vincent*, Michael J. Collins A topographical method to quantify scleral contact lens decentration. CLAE 2019

[21] Zeri F Punti e assi di riferimento degli occhi. In: Zeri F, Rossetti A, Fossetti A, Calossi A, editors. Ottica Visuale. Rome: SEU; 2012, p.315-361.

[22] McGraw K O, Wong S P. Forming interferences about some intraclass correlation coefficients. Psychol Methods 1996; 1 (1): 30-46.

[23] Landis J R, Koch G G. The measurement of observer agreement for categorical data. Biometrics 1977; 33 (1): 159-74.

[24] Woods RL, Colvin, CR, Vera-Diaz FA \& Peli E (2010). A relationship between tolerance of blur and personality. Invest Ophthalmol Vis Sci 51, 6077-6082.

[25] Zeri F, Beltramo I, Boccardo L, et al. An Italian translation and validation of the near activity visual questionnaire (NAVQ). Eur J Ophthalmol 2017;27: 640-645.

[26] Rosa AM, Miranda A^C, Patr' 1cio M, McAlinden C, Silva FL, Murta JN \& CasteloBranco M (2017). Functional magnetic resonance imaging to assess the neurobehavioral impact of dysphotopsia with multifocal intraocular lenses. Ophthalmology 124, 1280-1289.

[27] Zeri F, Naroo SA, Zoccolotti P, et al. Pattern of reading eye movements during monovision contact lens wear in presbyopes. Sci Rep 2018;22: 15574.

[28] Zeri F, Berchicci M, Naroo SA, et al. Immediate cortical adaptation in visual and nonvisual areas functions induced by monovision. J Physiol 2018;596: 253-266.

[29] Monsálvez-Romín D, Domínguez-Vicent A, García-Lázaro S, Esteve-Taboada JJ, Cerviño A. Power profiles in multifocal contact lenses with variable multifocal zone. Clinical and Experimental Optometry. 2018 Jan;101(1):57-63. 
[30] Madrid-Costa D, Ruiz-Alcocer J, García-Lázaro S, Ferrer-Blasco T, Montés-Micó R. Optical power distribution of refractive and aspheric multifocal contact lenses: effect of pupil size. Contact Lens and Anterior Eye. 2015 Oct 1;38(5):317-21

[31] Wagner S, Conrad F, Bakaraju RC, Fedtke C, Ehrmann K, Holden BA. Power profiles of single vision and multifocal soft contact lenses. Contact Lens and Anterior Eye. 2015 Feb $1 ; 38(1): 2-14$

[32] Dave T. Current developments in measurement of corneal topography. Contact Lens and Anterior Eye. 1998 Jan 1;21:S13-30. 